\title{
Laboreal
}

Volume $12 \mathrm{~N}^{\circ} 2$ | 2016

Equipamentos de Proteção Individual II

\section{(Acerca de la) Resiliencia organizacional}

(Sobre a) Resiliência organizacional

(À propos de la) Résilience organisationnelle

(About) organisational Resilience

\section{Jorge Walter}

\section{(2) OpenEdition}

\section{Journals}

Edición electrónica

URL: http://journals.openedition.org/laboreal/2766

DOI: 10.4000/laboreal.2766

ISSN: 1646-5237

\section{Editor}

Universidade do Porto

\section{Referencia electrónica}

Jorge Walter, « (Acerca de la) Resiliencia organizacional », Laboreal [En línea], Volume 12 №2 | 2016,

Publicado el 01 diciembre 2016, consultado el 15 septiembre 2020. URL : http:// journals.openedition.org/laboreal/2766

Este documento fue generado automáticamente el 15 septiembre 2020.

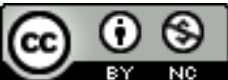

Laboreal está licenciado com uma Licença Creative Commons - Atribuição-NãoComercial 4.0 Internacional. 


\title{
(Acerca de la) Resiliencia organizacional
}

\author{
(Sobre a) Resiliência organizacional \\ (À propos de la) Résilience organisationnelle \\ (About) organisational Resilience
}

Jorge Walter

\section{NOTA DEL EDITOR}

http://dx.doi.org/10.15667/laborealxii0216jw

1 Resiliencia alude a la propiedad de un sistema de recuperarse tras haber sufrido una alteración. Retomamos al respecto la siguiente definición: "rasgo que tienen algunos sistemas y que les permite responder a necesidades repentinas y no anticipadas para la actuación y después volver a su condición normal de funcionamiento con rapidez y con una mínima merma de su rendimiento" (Cook \& Nemeth 2013, p.321) y, en el mismo libro de donde tomamos esta cita, la definición propuesta por sus editores: "la característica fundamental de una organización con resiliencia es que no pierde el control de lo que hace sino que es capaz de continuar y rebotar" (Hollnagel, Woods \& Levenson, 2013, p.378) o, dicho en otros términos, de recuperarse y continuar funcionando. Respecto a la primera definición, conviene evitar toda ambigüedad prestando atención a la siguiente aclaración de los editores del libro: la resiliencia no es una propiedad "que tiene" el diseño del sistema (que se logra "simplemente introduciendo más procedimientos, protecciones y barreras") sino el producto de un "control continuo de su actuación" (...) "que se produzca un suceso no deseado no significa necesariamente que la seguridad como tal haya fallado, sino que podría deberse igualmente al hecho de que la seguridad nunca es completa o absoluta (Hollnagel et al., 2013, p.377). Para explicar lo anterior recurren al concepto de racionalidad limitada acuñado por Herbert Simon a fines de los años cuarenta del siglo pasado para criticar la pretendida racionalidad omnisciente del diseño basado en el 
"estudio científico de la organización del trabajo" por parte de pensadores clásicos de la administración como Taylor o Fayol, pues "no siempre hay suficiente tiempo para ser lo suficientemente minucioso" (y) "de hecho el factor más importante es probablemente la necesidad de obtener tiempo para evitar perder el control, como se ha descrito en el compromiso eficiencia-minuciosidad (Hollnagel, 2009, p.175)". Dicho en otros términos: las soluciones reales se aportan normalmente bajo presión temporal, bajo la influencia de puntos de vista sesgados y con información no exhaustiva sino apenas suficiente, dado lo cual nunca son perfectas y son fuente de nuevos problemas que permanecen latentes en el sistema a la espera de una ocasión para volverse manifiestos. Dicho esto, el énfasis en la recuperación del funcionamiento normal del sistema convierte al concepto de resiliencia en tributario de la literatura sobre gestión de crisis. La clave de la resiliencia no reside, en efecto, en la adaptación o el aprendizaje ("un sistema que se limite a confiar en la retroalimentación perderá tarde o temprano el control" (op.cit., p.378) sino en la resistencia y la recuperación del estado previo. Dado lo cual la literatura sobre el tema se ha enfocado sobre dos aspectos concomitantes de la cuestión: a) la gravedad de la catástrofe (que puede y debe dimensionarse, así como se evalúan los niveles de riesgo) y, b) la capacidad de reacción del sistema frente a ella. Lo ha hecho en tres niveles: individual (abuso sexual, por ejemplo), grupal (un equipo de bomberos enfrentando un incendio forestal que puede rodearlo) y organizacional (las empresas con sede en las Torres Gemelas en Nueva York tras los eventos de setiembre de 2001). El ejemplo referido al abuso sexual ilustra claramente el modo de razonamiento: la recuperación de la persona es más difícil cuando la violación es reiterada y cuando la agresión proviene del entorno familiar (y viceversa). La recuperación es más fácil cuando la víctima es sociable, milita en alguna causa y tiene algún tipo de hobby que la ayude a distraerse (y viceversa). Hemos resumido esta literatura en un texto publicado un año después de la caída de las torres, motivados por la grave crisis que enfrentaba en ese momento la Argentina (Walter, 2002). Desde un punto de vista preventivo, las medidas recomendadas a partir del estudio del fenómeno consistían en: a) anticipar la emergencia de un desastre mediante la detección de eventos precursores ("pródromos", como en medicina se denominan los síntomas que preceden el comienzo de una enfermedad o la inminencia de un parto), b) reforzar la resistencia del sistema para enfrentar tales sucesos y, c) crear sistemas específicos para la gestión de las situaciones de emergencia. En el libro de Hollnagel et al. (2013) se comenta el caso de un tsunami que afectó la costa oeste de los EEUU, que dio origen a una alerta confusa, que además nunca llegó: "Tras el tsunami que todos recordamos sucedido en el sudeste asiático en diciembre de 2004 se implementaron sistemas de alerta temprana en diferentes lugares del mundo. En junio del año siguiente sucedió un terremoto cerca de California y los nuevos sistemas ya estaban preparados para actuar. La detección del sismo fue realizada por dos centros, el primero de ellos ubicado en Alaska y, tres minutos más tarde, por un centro ubicado en Hawái. Este último informó que no había riesgo de Tsunami, pero no se refería a la costa Oeste de EEUU, lo cual sembró la confusión entre los rescatistas californianos. Por otra parte, ciertas regiones costeras de California con las cuales solo se mantenían comunicaciones telefónicas no recibieron advertencia alguna a causa de un fallo inadvertido en las líneas de comunicación. Aunque se habían tomado las precauciones y los procedimientos estaban preparados, no se sabía si en realidad funcionaban y no se sabía cuáles eran las condiciones reales (...) Aunque el sistema estaba diseñado para buscar factores específicos en el entorno, no estaba diseñado para observarse a sí 
mismo (...) no estaba diseñado para tener resiliencia" (Hollnagel et al., 2013, p.382). ¿Qué puede aportar a su turno, respecto a la resiliencia, la gestión de riesgos a la gestión de las crisis? La teoría de las organizaciones de alta confiabilidad (high reliability organisations) puso en evidencia el rol clave del operador de primera línea en la detección de los eventos precursores gracias a su percepción directa de los sucesos anómalos en el lugar y el momento mismo en los que se producen. Se convierte así en la fuente principal de alertas tempranas (Roberts, Stout \& Halpern, 1994). La valorización y el reforzamiento de su rol en la organización - dotándolo de los recursos que necesita para ello - es clave para la anticipación de los problemas antes de que sucedan - o sus consecuencias se agraven - y para que la intervención rápida tenga lugar según procedimientos predefinidos y con el apoyo inmediato de equipos gerenciales especialmente constituidos. Respecto a éstos últimos, Hollnagel y sus colegas consideran que una habilidad clave es la "imaginación necesaria" consistente en "ir más allá de la experiencia, esperar lo inesperado y buscar algo más que simplemente lo obvio" (Hollnagel et al., 2013, p.379). Esta habilidad se relaciona con la integración en el razonamiento de los gerentes y técnicos de lo que Perrow (2009) denomina "complejidad interactiva", que les permite escapar al reduccionismo que caracteriza la racionalidad limitada. También está relacionado con la "capacidad del sistema para observarse a sí mismo", es decir, con la aptitud y la voluntad autocrítica de sus miembros.

\section{BIBLIOGRAFÍA}

Cook, R.I., \& Nemeth, C. (2013). "Tomando las cosas con calma. Rasgos cognitivos de dos actuaciones con resiliencia." In E. Hollnagel, D. D. Woods, y N. Levenson (Eds.), Ingeniería de la resiliencia. Conceptos y preceptos (pp. 231-249). Valencia: Modus Laborandi.

Hollnagel, E. (2009). Barreras y prevención de accidentes, Madrid: Modus Laborandi. (Obra publicada originalmente en inglés, en 1988).

Hollnagel, E., Woods, D.D., \& Levenson, N. (Eds.) (2013). Ingeniería de la resiliencia. Conceptos y preceptos, Valencia: Modus Laborandi. (Obra publicada originalmente en inglés, en 2006).

Perrow, C. (2009). Accidentes Normales. Convivir con las tecnologías de alto riesgo. Madrid: Ed. Modus Laborandi. (Obra publicada originalmente en inglés, en 1986).

Reason, J. (2008). El Error Humano. Madrid, Ed. Modus Laborandi. (Obra publicada originalmente en inglés, en 1991).

Roberts, K. H., Stout, S. K., \& Halpern, J. J. (1994). Decision Dynamics in Two High Reliability Military Organizations, Management Science, vol. 40, 5, pp.614-624.

Walter, J. (2002). Tecnologías de Gestión. Revista Encrucijadas, 2, 20, pp.64-72. 
ÍNDICE

Temas: O Dicionário

\section{AUTOR}

\section{JORGE WALTER}

Consejo Nacional de Investigaciones Científicas y Técnicas (CONICET). Centro de Investigaciones por una Cultura de Seguridad de la Escuela de Administración y Negocios de la Universidad de San Andrés.

Vito Dumas 284, Victoria, Provincia de Buenos Aires, Argentina

walter@udesa.edu.ar 